\title{
Defect Creation by Linker Fragmentation in Metal-Organic Frameworks and Its Effects on Gas Uptake Properties
}

\author{
Gokhan Barin, ${ }^{\dagger}$ Vaiva Krungleviciute, ${ }^{\ddagger}, \S$ Oleksii Gutov, ${ }^{\dagger}$ Joseph T. Hupp, ${ }^{* \dagger}$ Taner Yildirim, ${ }^{*, \neq, \S}$ \\ and Omar K. Farha* ${ }^{* \dagger, \perp}$ \\ ${ }^{\dagger}$ Department of Chemistry, Northwestern University, 2145 Sheridan Road Evanston, Illinois 60208, United States \\ ${ }^{\ddagger}$ NIST Center for Neutron Research, National Institute of Standards and Technology, Gaithersburg, Maryland 20899, United States \\ ${ }^{\S}$ Department of Materials Science and Engineering, University of Pennsylvania, Philadelphia, Pennsylvania 19104, United States \\ ${ }^{\perp}$ Department of Chemistry, Faculty of Science, King Abdulaziz University, Jeddah 22254, Saudi Arabia
}

\section{Supporting Information}

\begin{abstract}
We successfully demonstrate an approach based on linker fragmentation to create defects and tune the pore volumes and surface areas of two metal-organic frameworks, NU-125 and HKUST-1, both of which feature copper paddlewheel nodes. Depending on the linker fragment composition, the defect can be either a vacant site or a functional group that the original linker does not have. In the first case, we show that both surface area and pore volume increase, while in the second case they decrease. The effect of defects on the high-pressure gas uptake is also studied over a

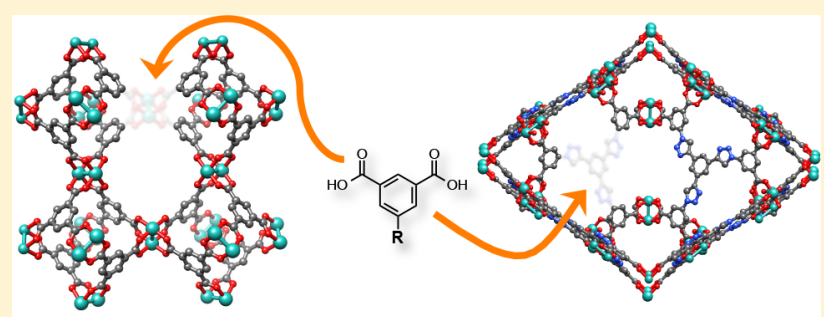

HKUST-1

NU-125 large temperature and pressure range for different gases. We found that despite an increase in pore volume and surface area in structures with vacant sites, the absolute adsorption for methane decreases for HKUST-1 and slightly increases for NU-125. However, the working capacity (deliverable amount between 65 and 5 bar) in both cases remains similar to parent frameworks due to lower uptakes at low pressures. In the case of NU-125, the effect of defects became more pronounced at lower temperatures, reflecting the greater surface areas and pore volumes of the altered forms.
\end{abstract}

\section{INTRODUCTION}

Metal-organic frameworks (MOFs) are an attractive class of porous materials on account of their relative simplicity and increasing predictability in their construction. ${ }^{1-3}$ The reversible nature of coordination bonds between organic linkers and metal ions/clusters renders MOFs highly ordered crystalline materials, which, in turn, results in high surface areas and pore volumes. ${ }^{4-6}$ Such properties have proven to be useful in a wide range of applications, including but not limited to gas storage ${ }^{7-10}$ gas separations, ${ }^{11-14}$ catalysis, ${ }^{15,16}$ electrochromism, ${ }^{17,18}$ and chemical sensing. ${ }^{19,20}$ The judicious selection of building blocks, be it organic linkers or metal nodes, allows for tremendous control over surface area and porosity, while new synthesis techniques ${ }^{21}$ permit the incorporation of a wide variety of functional groups into the framework. Although early synthesis work focused on rather simple symmetrical organic linkers, the field has transitioned to the use of extended organic linkers in an effort to reach ever higher surface areas and pore volumes, thereby increasing the capacity of MOFs, particularly for gas storage purposes. Additionally, postsynthetic modification (PSM) $)^{22-24}$ and solvent-assisted linker exchange (SALE) $)^{23,25-29}$ have emerged as effective approaches for finetuning the properties of MOFs for desired applications. Unfortunately, linker modification/elaboration often results in significant reductions in molecule-accessible surface areas and pore volumes, with concomitant damage to MOF capacities for gas storage.

Alternatively, mixed-linker approach has proven ${ }^{30-33}$ to be a promising strategy in which cocrystallization or copolymerization of at least two different organic building blocks results in the formation of a network of mixed functionalities. An earlier report by Matzger and co-workers demonstrated ${ }^{34,35}$ that copolymerization of two structurally distinct linkers with identical coordination sites produces a new material (UMCM-1), properties of which outperform those obtained from pure linkers. Yaghi group utilized ${ }^{36}$ the mixed-linker approach to prepare a series of multivariate MOFs (MTVMOF-5) using linear linkers such as terephthalate and its derivatives. More recently, Zhou and co-workers reported ${ }^{37}$ a coassembly approach using NOTT-101/PCN-125. Moreover, depending on the fragment used during cocrystallization, not only are certain functional groups incorporated into the MOF, pore environment is also altered as a result of linker fragmentation. As an example, we have recently shown that it is possible to tune the pore volume of a zirconium-based MOF, UiO-66, from $0.4 \mathrm{cc} / \mathrm{g}$ to $1.0 \mathrm{cc} / \mathrm{g}$ continuously by replacing dicarboxylic acid linker with acetic acid. ${ }^{38}$ In all approaches

Received: March 27, 2014

Published: June 6, 2014 
mentioned above, mixed linkers are incorporated into the framework as a result of having identical coordination sites and comparable reactivities.

The fact that parent framework-which is solely made from the linker component-is maintained in the mixed linkerfragment approach makes this strategy promising to fine-tune and/or maximize the gas sorption properties of MOFs that already perform well. We envisioned that MOFs exhibiting rht topology would be an ideal platform to explore the effects of linker fragmentation on gas sorption properties since these materials have been demonstrated ${ }^{5,39-46}$ to be promising in $\mathrm{H}_{2}$, $\mathrm{CH}_{4}$, and $\mathrm{CO}_{2}$ storage at high pressures. The rht topology is a $(3,24)$-connected network constructed from hexacarboxylic acid linkers and paddlewheel-type metal nodes. ${ }^{47}$ The key feature of this topology is that network interpenetration is not allowed, thus resulting in high porosity and large surface areas. Subsequently, when linker fragmentation strategy is employed, the resulting frameworks would easily accommodate bulky fragments in addition to the smaller analogues. In the former case, interior decoration of the frameworks with bulky functionalities could be achieved, whereas, in the latter case, pore volume would be increased as a result of replacement of the linker component with less bulkier fragments.

In this present work, we successfully employed (Figure 1) the mixed linker-fragment approach using parent frameworks NU-125 ${ }^{48}$ with an $r$ th topology and HKUST-1, ${ }^{49}$ both of which have been reported ${ }^{50}$ as promising materials for $\mathrm{CH}_{4}$ and $\mathrm{CO}_{2}$ storage. Two different fragments, F1 (isophthalic acid) and F2 (5-perfluorobutylisophthalic acid), were utilized to obtain the corresponding mixed linker MOFs NU-125-F1 and NU-125F2, respectively, while only F1 was used to modify the pore environment of HKUST-1, resulting in a new structure HKUST-1-F1. The preparation and characterization of the resulting MOFs as well as the effect of linker fragmentation on the porosity and the high-pressure gas $\left(\mathrm{H}_{2}, \mathrm{CH}_{4}\right.$, and $\left.\mathrm{CO}_{2}\right)$ uptake are described.

\section{RESULTS AND DISCUSSION}

As mentioned above, both NU-125 and HKUST-1 are promising materials for storage applications, and, therefore, we decided to start with exploring the mixed linker-fragment approach using isophthalic acid (F1) as a fragment in both materials. The presence of isophthalic acid moieties within the framework should result (Figure 1) in "defect" or "vacant" sites, which could potentially increase the surface areas and pore volumes. Since both NU-125 and HKUST-1 have been recently shown ${ }^{50}$ to have record high methane uptakes, it would be interesting to see if any small structural perturbation in these MOFs can increase their methane uptake capacity further. We also tested the possibility of incorporating bulky fluorinated fragments into the NU-125 framework as an example of pore functionalization.

Both NU-125 and HKUST-1 consist of copper paddlewheels as the secondary building units. NU-125 has four different cages with almost 11, 15, 16, and $24 \AA$ diameters, whereas HKUST-1 has small cages with diameters of 4,10 , and $11 \AA$. Since both MOFs are relatively robust and stable, these frameworks should be able to accommodate missing linkages. The resulting frameworks were characterized by powder X-ray diffraction (PXRD), ${ }^{1} \mathrm{H}$ and ${ }^{19} \mathrm{~F}$ NMR spectroscopy, and $\mathrm{N}_{2}$ adsorption measurements.

The synthesis of linker L was previously reported, ${ }^{48,51}$ and both btc and F1 are commercially available. The fragment F2
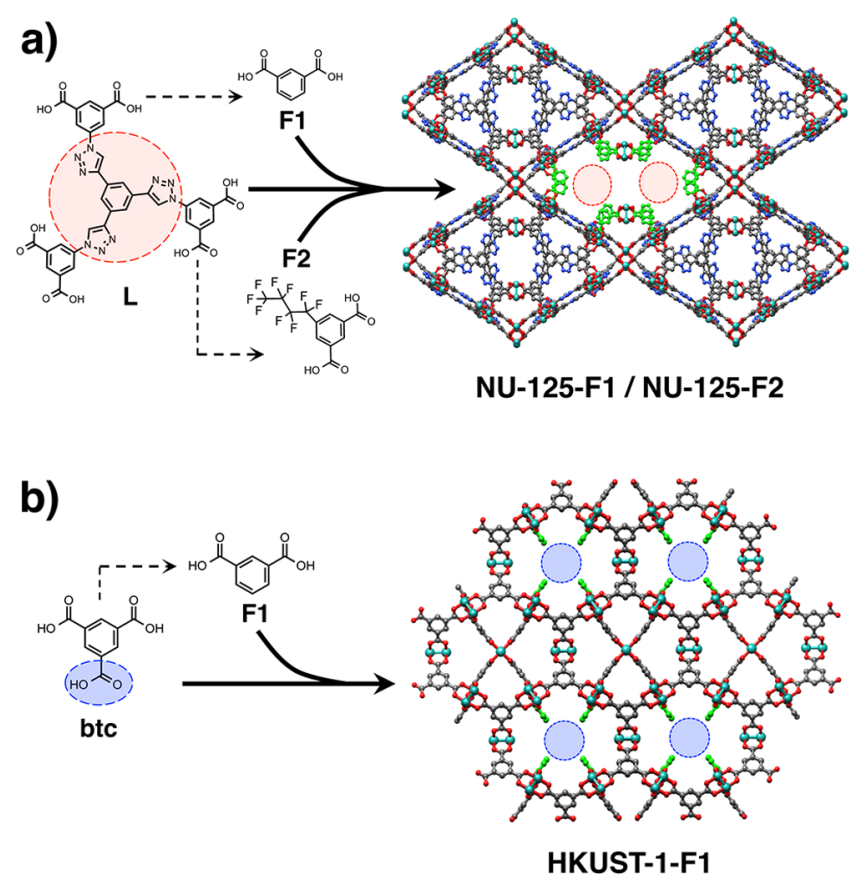

Figure 1. (a) The structural formula of linker $\mathbf{L}$ and its two possible fragments; isophthalic acid (F1) and 5-perfluorobutylisophthalic acid (F2) and the representative illustration of the mixed linker-fragment MOFs NU-125-F1 and NU-125-F2 obtained using the single-crystal $\mathrm{X}$-ray structure of the parent framework NU-125. The incorporation of fragments results in the missing linkages (represented by red circles) between copper paddlewheels, and, therefore, it either increases the pore volume as in NU-125-F1 or creates functionalized pores as in the case of NU-125-F2. (b) The representative structure of HKUST-1-F1, generated by using the single-crystal X-ray structure of HKUST-1, incorporating the fragment F1. The inclusion of F1 into the parent HKUST-1 structure leads to the occurrence of missing copper paddlewheels (represented by blue circles) as opposed to linker fragmentation. Most likely, the distribution of these defect sites (red or blue circles) is random in the resulting mixed linker-fragment MOFs.

carrying a perfluorobutyl chain was prepared using a procedure modified from the literature and detailed in the Supporting Information. General synthetic scheme for the synthesis of mixed linker-fragment MOFs using NU-125 as the parent framework involves (Figure 1a) the solvothermal reaction between $\mathrm{Cu}\left(\mathrm{NO}_{3}\right)_{2} \cdot 2.5 \mathrm{H}_{2} \mathrm{O}$ and a mixture of $\mathrm{L}$ and the fragment $\mathbf{F 1}$ or $\mathbf{F} 2$ in $N, N$-dimethylformamide (DMF) at 80 ${ }^{\circ} \mathrm{C}$. Similarly, for HKUST-1 as the parent framework (Figure 1b), a mixture of $\mathrm{Cu}\left(\mathrm{NO}_{3}\right)_{2} \cdot 2.5 \mathrm{H}_{2} \mathrm{O}$, linker btc, and $\mathbf{F 1}$ was mixed in DMF and kept at $80{ }^{\circ} \mathrm{C}$ to obtain a teal-colored crystalline material. Varying feed ratios (fragment/linker) were examined (see the Supporting Information) to maximize the incorporation of fragments without altering the structure of the parent frameworks, as monitored by PXRD.

We determined that the optimum feed ratio for fragment $\mathbf{F} \mathbf{1}$ was 3:1 (NU-125-F1), whereas that for F2 was 2:1 (NU-125F2), in which PXRDs remained (Figure 2a) unchanged when compared to NU-125. The degree of fragment incorporation in the resulting frameworks, after washing the as-synthesized materials thoroughly with DMF, was determined (see the Supporting Information) using ${ }^{1} \mathrm{H}$ NMR spectroscopy after digesting the crystals in a mixture of deuterated dimethyl sulfoxide and deuterated hydrochloric acid (DMSO- $\left.d_{6} / \mathrm{DCl}\right)$. The appearance of fragment peaks (F1 and F2) in addition to 

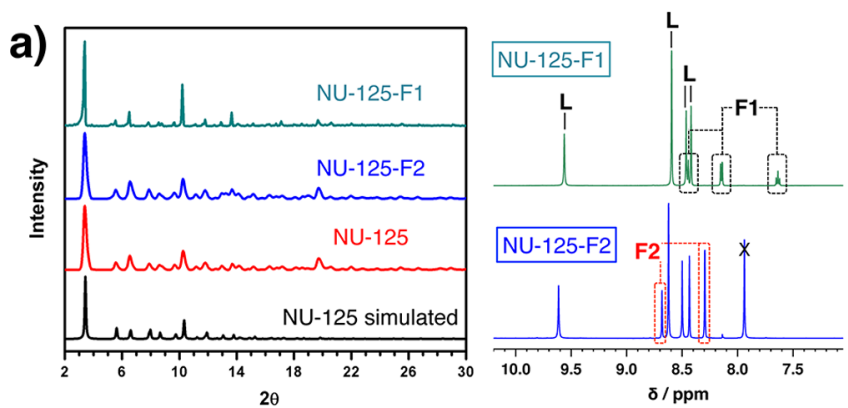

b)
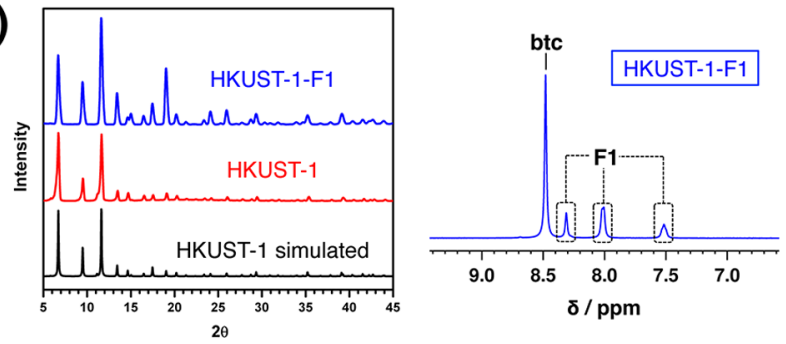

Figure 2. (a) PXRD patterns of NU-125-F1 and NU-125-F2 obtained from feed ratios (fragment/linker) of 3:1 and 2:1, respectively, as well as the parent framework NU-125. Both patterns are in good agreement with that of NU-125, indicating that they are isostructural to the parent material. The presence of fragments F1 and F2 and the degree of their incorporation were determined by ${ }^{1} \mathrm{H}$ NMR spectroscopy of intentionally dissolved samples. (b) The PXRD pattern of HKUST-1-F1 is also in good agreement with the simulated pattern of the parent framework HKUST-1. The ${ }^{1} \mathrm{H}$ NMR spectroscopy also revealed the incorporation of F1 into HKUST-1F1. Crystals were washed with DMF thoroughly and then digested in DMSO $-d_{6} / \mathrm{DCl}$ before acquiring the ${ }^{1} \mathrm{H}$ NMR spectra.

that of linker $\mathbf{L}$ in the ${ }^{1} \mathrm{H}$ NMR spectrum illustrates (Figure 2a) the presence of fragments in NU-125-F1 and NU-125-F2. Furthermore, ${ }^{19} \mathrm{~F}$ NMR spectroscopy was applied to demonstrate the incorporation of F2 into the NU-125-F2 (Supporting Information, Figure S5). Different degrees of fragment incorporation can be explained by different reactivities of these two distinct fragments. The possibility of mixed phases formed separately by pure linker and pure fragment were ruled out since the pure fragment forms a completely different structure, as evidenced by PXRD (Supporting Information, Figure S3). Surface attachment of fragments was also considered; however, control experiments revealed (Supporting Information, Figure S6) that when the parent framework was soaked into a DMF solution of F1 or F2, no fragment incorporation or attachment was observed by ${ }^{1} \mathrm{H}$ NMR spectroscopy. In the case of HKUST-1-F1, a feed ratio (F1/ btc) of 2:1 was found (Supporting Information, Figure S7) to be optimal for the incorporation of F1 into the HKUST-1 parent framework. The PXRD pattern of HKUST-1-F1 agrees (Figure 2b) well with that of HKUST-1, indicating that (at this feed ratio) the incorporation of F1 does not alter the structure of parent framework and remains isostructural. ${ }^{1} \mathrm{H}$ NMR spectroscopy also revealed the peaks associated with F1 protons, which were compared to that of btc to determine the ratio between fragment and linker in the crystals. In all cases, as the feed ratio is increased, higher incorporation of fragment into the framework is also achieved (see the Supporting Information). The formation of a mixed linkerfragment structure rather than a mixture of two different phases is most likely a result of similar reactivities of linkers ( $\mathbf{L}$ and btc) and fragments (F1 and F2) examined here. Therefore, fragments cannot be distinguished during the crystallization process and are included in the resulting frameworks.

To demonstrate the effect of the linker fragmentation on porosity and surface area, we compared the nitrogen isotherms of the mixed linker-fragment MOFs with that of respective parent structures (see Figure 3). The details of the pore volume/surface area analysis are given in the Supporting Information (see Figures S9-S16). In the case of NU-125-F1, we expected an increase in both pore volume and surface area since the central part of the linker $\mathbf{L}$ is removed upon incorporation of fragment F1. Indeed, this was the case, as shown in Figure 3a. The pore volume and surface area are increased by $15 \%$ from $1.30 \mathrm{cc} / \mathrm{g}$ and $3225 \mathrm{~m}^{2} / \mathrm{g}$ (for NU-125) to $1.45 \mathrm{cc} / \mathrm{g}$ and $3680 \mathrm{~m}^{2} / \mathrm{g}$. For NU-125-F2, we expect a decrease in the pore volume and surface area as fragment F2 introduces additional functional groups into the pores. Figure $3 \mathrm{~b}$ shows that the pore volume of NU-125-F2 is $1.05 \mathrm{cc} / \mathrm{g}$, about $20 \%$ decrease from $1.30 \mathrm{cc} / \mathrm{g}$ for the parent NU-125. Interestingly, the surface area decreased to $2380 \mathrm{~m}^{2} / \mathrm{g}$ from $3225 \mathrm{~m}^{2} / \mathrm{g}$, roughly a $37 \%$ decrease. These results suggest that we successfully incorporated the fragments F1 and F2 into the structure and tuned both pore volumes and surface areas along with introducing functional groups in the pores. Similar to that of NU-125-F1, HKUST-1-F1 has an increased pore volume of $0.85 \mathrm{cc} / \mathrm{g}$ from $0.78 \mathrm{cc} / \mathrm{g}$ (parent HKUST-1) upon fragment

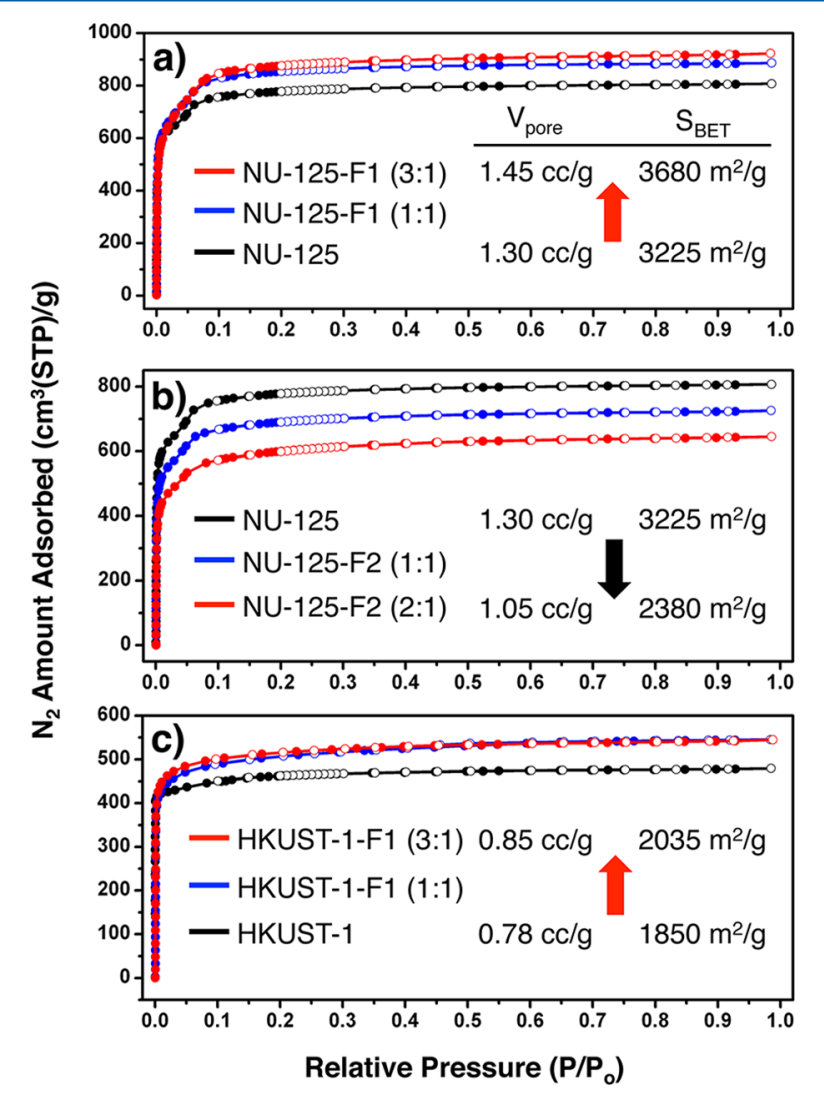

Figure 3. (a) $\mathrm{N}_{2}$ isotherms of NU-125-F1 at feed ratios (F1/L) of 3:1 (red), 1:1 (blue), and 0:1 (black, parent NU-125). The pore volumes $(\mathrm{cc} / \mathrm{g})$ and surface areas $\left(\mathrm{m}^{2} / \mathrm{g}\right)$ are also indicated. (b) Same as above but for NU-125-F2. (c) Same as above but for HKUST-1. Closed and open symbols represent adsorption and desorption branches, respectively. 
incorporation. The surface area is also increased to $2035 \mathrm{~m}^{2} / \mathrm{g}$ from $1850 \mathrm{~m}^{2} / \mathrm{g}$, as shown in Figure 3c.

Since HKUST-1 is the current record holder for volumetric methane uptake, ${ }^{50,52}$ it is interesting to see if the $10 \%$ increase in the pore volume and surface area in HKUST-1-F1 will further increase the methane uptake of HKUST-1. To check this hypothesis, we measured room temperature gas uptakes for various gases including $\mathrm{H}_{2}, \mathrm{~N}_{2}, \mathrm{CH}_{4}$, and $\mathrm{CO}_{2}$. The results are shown in Figure 4. Despite the $15 \%$ increase in pore volume
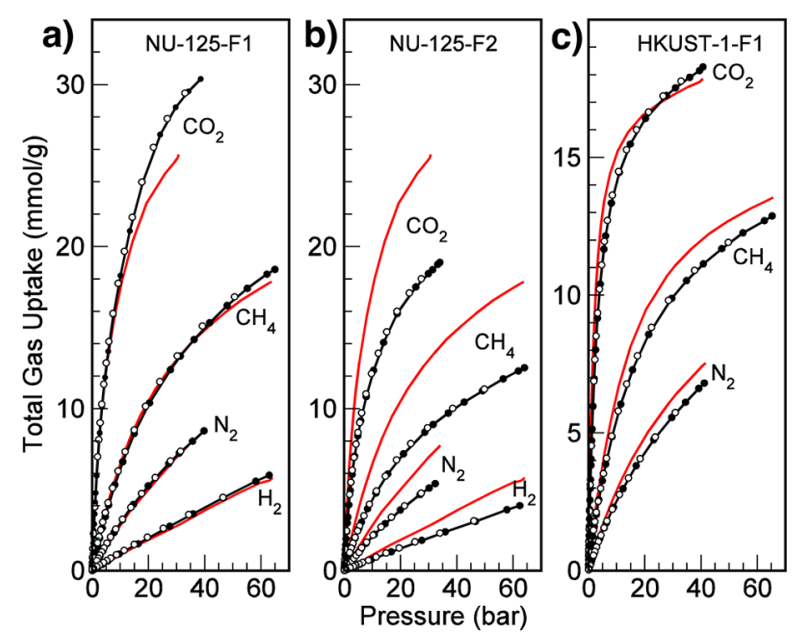

Figure 4. Total gas uptake for various gases at room temperature for (a) NU-125-F1, (b) NU-125-F2, and (c) HKUST-1-F1. The red curves show the isotherms for the parent MOFs, i.e., NU-125 (a, b) and HKUST-1 (c).

and surface area for NU-125-F1, its high-pressure gas uptake properties were found to be very similar to those of parent NU125, which are shown as red lines in Figure 4. The only difference appears at high pressures, indicating that the additional surface area created by F1 incorporation has weak binding sites that are not populated at low pressures. Interestingly, the F1-substitution has the largest effect on the maximum $\mathrm{CO}_{2}$ uptake, which increases from to $\sim 25 \mathrm{mmol} / \mathrm{g}$ to $\sim 30 \mathrm{mmol} / \mathrm{g}$ at $30 \mathrm{bar}$. As expected, the incorporation of fragment F2 in NU-125-F2 significantly decreases its gas uptake capacities, as shown in Figure $4 \mathrm{~b}$. We should note that our goal here was to show that we could incorporate functional groups in NU-125 (in this case perfluorobutyl chains). One can imagine that another fragment moiety, which has, for instance, dangling amine $\left(-\mathrm{NH}_{2}\right)$ groups instead of a perfluorobutyl chain, could be used to tune the $\mathrm{CO}_{2}$ capture properties of NU125.

Interestingly, the $10 \%$ increase in the pore volume and surface area in HKUST-1 upon F1 incorporation had apparently a much larger effect on its gas uptake properties (Figure 4c) when compared to NU-125-F1. The maximum high-pressure uptakes for $\mathrm{CH}_{4}$ and $\mathrm{N}_{2}$ are actually lower by $6 \%$ and 14\% in HKUST-1-F1 compared to parent HKUST-1. This suggests that, with the incorporation of $\mathbf{F} 1$ in the pores, we are removing copper paddlewheel clusters to create defect sites and, therefore, decreasing the number of gas adsorption sites with higher binding energy or increasing the optimal pore size for methane. It seems that the additional pore volume/surface area created by $\mathbf{F} \mathbf{1}$ does not provide strong binding sites for $\mathrm{CH}_{4}$ and $\mathrm{N}_{2}$ at room temperature. In the case of $\mathrm{CO}_{2}$, the total isotherm measured on HKUST-1 with F1 fragment is initially lower than that measured in the parent sample (Figure 4c); at high pressures, the isotherms cross each other, and we get a slight increase in the total uptake for HKUST-1-F1 compared to parent HKUST-1. Since the $\mathrm{CO}_{2}$-host interaction is larger compared to $\mathrm{N}_{2}$ and $\mathrm{CH}_{4}$, it can take advantage of the additional surface area and pore volume at high pressures.

In the context of methane storage, in addition to achieving high methane uptake, another important factor to consider is the working capacity, which can be defined as the deliverable amount of methane between 65 bar (upper storage pressure) and 5 bar (lower pressure limit at which the natural gas engine operates). Hence, we checked the working capacity of HKUST1-F1 shown in Figure $4 \mathrm{c}$ and obtained $\sim 9.6 \mathrm{mmol} / \mathrm{g}$ (i.e., $12.9-3.3 \mathrm{mmol} / \mathrm{g}$ ), which is interestingly the same as parent HKUST-1 (i.e., $13.5 \mathrm{mmol} / \mathrm{g}$ (at $65 \mathrm{bar}$ ) $-3.9 \mathrm{mmol} / \mathrm{g}$ (at 5 bar)). This is a nice demonstration that by weakening the initial $\mathrm{CH}_{4}$ binding energy, it is possible to retain the working capacity even though the total capacity is decreased as a net effect of F1 incorporation. To get a better feeling of the nature and concentration of the copper paddlewheel clusters, we created (see the Supporting Information) simple models of HKUST-1F1 by removing one and two $\mathrm{Cu}_{2}\left(\mathrm{CO}_{2}\right)_{4}$ clusters from the parent HKUST-1 conventional cell. The calculated pore volume and surface area values suggest that we have approximately two $\mathrm{Cu}_{2}\left(\mathrm{CO}_{2}\right)_{4}$ clusters missing in the conventional unit cell, which has $24 \mathrm{Cu}_{2}\left(\mathrm{CO}_{2}\right)_{4}$ clusters in a perfect HKUST-1 structure. Using the crystal density of this defective structure, we estimated that the volumetric working capacity of HKUST-1-F1 is also very similar to parent HKUST-1.

To get a better insight into the nature of adsorption sites and interactions as a result of linker fragmentation in NU-125, we also studied $\mathrm{CH}_{4}, \mathrm{CO}_{2}$, and $\mathrm{H}_{2}$ uptake properties over wide temperature and pressure ranges. The absolute isotherms for NU-125-F1 are shown in Figure 5. The temperature-dependent isotherms for NU-125-F2 along with other excess isotherms are shown in the Supporting Information (Figures S17-22). As illustrated in Figure 5, even though the room temperature uptakes are very similar to those of parent NU-125, the difference between NU-125 and NU-125-F1 becomes more evident at lower temperature. This behavior is a result of additional pore volume and surface area available in NU-125F1 that is occupied at lower temperatures. The $\mathrm{CH}_{4}$ isotherm at $125 \mathrm{~K}$ was collected up to the saturation pressure. The maximum adsorption at the saturation pressure $(34.8 \mathrm{mmol} / \mathrm{g}$ ) yields a pore volume of $1.43 \mathrm{cc} / \mathrm{g}$, which is slightly lower than the nitrogen pore volume of $1.45 \mathrm{cc} / \mathrm{g}$ (Supporting Information, Figure S16). Similarly, we measured the saturation isotherm of $\mathrm{CO}_{2}$ at $220 \mathrm{~K}$ and obtained $38.1 \mathrm{mmol} / \mathrm{g}$ and $V_{\text {pore }}\left(\mathrm{CO}_{2}\right)=1.44 \mathrm{cc} / \mathrm{g}$. These results suggest that both $\mathrm{CO}_{2}$ and $\mathrm{CH}_{4}$ can access the same pores in NU-125-F1 that $\mathrm{N}_{2}$ accesses at $77 \mathrm{~K}$ despite their larger kinetic diameters. It may be that introducing defects by linker fragmentation favorably assists the kinetics and diffusion of gas molecules. Finally, in the case of $\mathrm{H}_{2}$, we note that at temperatures above $150 \mathrm{~K}$, the isotherms from parent and mixed linker-fragment MOFs are almost the same, again reflecting weak $\mathrm{H}_{2}$-surface interactions. The difference between NU-125-F1 and parent NU-125 starts to appear below $100 \mathrm{~K}$ and reaches the maximum in the isotherm measured at $30 \mathrm{~K}$ where the temperature is low enough to adsorb $\mathrm{H}_{2}$ molecules in all available pores/surfaces.

We also extracted isosteric heats of adsorption $\left(Q_{s t}\right)$ from the temperature-dependent total adsorption isotherms (see the Supporting Information for details) and summarized the results 

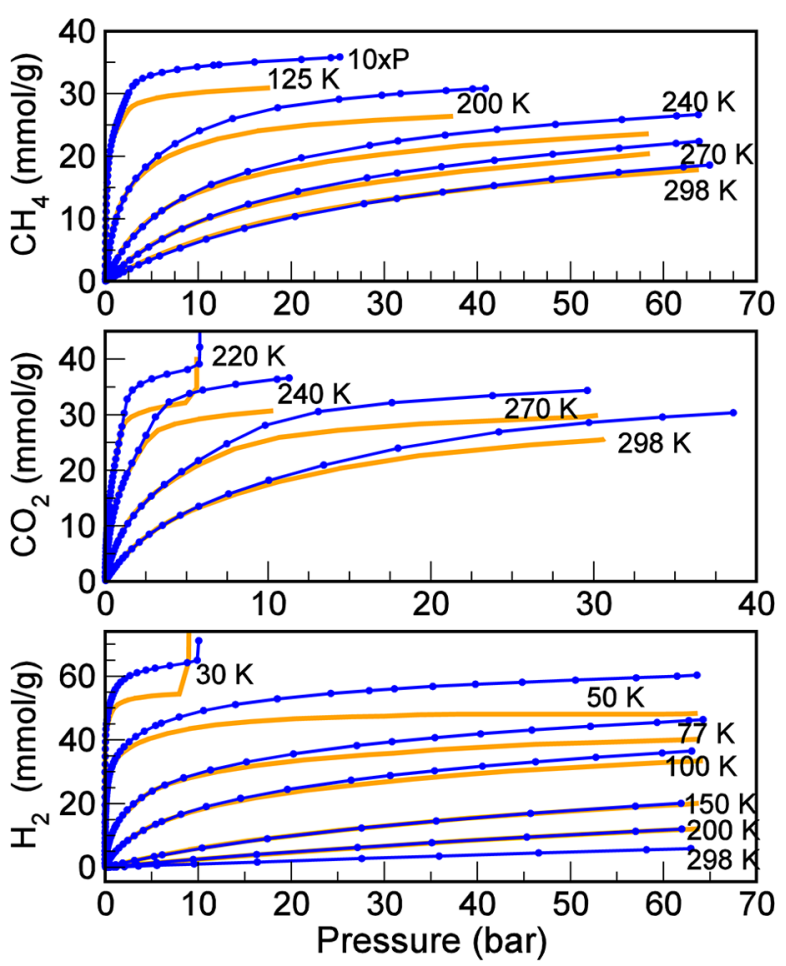

Figure 5. Total gravimetric gas uptake $(\mathrm{mmol}(\mathrm{gas}) / \mathrm{g}(\mathrm{MOF}))$ at various temperatures. The blue lines with filled circles are experimental data for NU-125-F1, while the orange lines are isotherms for the parent material NU-125.

in Figure 6. For $\mathrm{H}_{2}$, a weakly interacting gas molecule, the value of $Q_{s t}$ in the low-loading limit is insensitive to linker-fragment incorporation and is around $5 \mathrm{~kJ} / \mathrm{mol}$. At higher loadings, however, we see smaller $Q_{s t}$ values: $2.9 \mathrm{~kJ} / \mathrm{mol}$ (at $25 \mathrm{mmol} / \mathrm{g}$ loading) for NU-125-F2 and $3.5 \mathrm{~kJ} / \mathrm{mol}$ for NU-125-F1, compared to $4.0 \mathrm{~kJ} / \mathrm{mol}$ for the parent NU-125. The situation is very different for $\mathrm{CH}_{4}$. The $Q_{\mathrm{st}}$ for NU-125-F1 is the lowest among the three MOFs and is roughly constant at ca. $14 \mathrm{~kJ} /$ mol. The initial $Q_{s t}$ for parent NU-125 and NU-125-F2 is almost the same, around $16 \mathrm{~kJ} / \mathrm{mol}$. The lower and almost constant $Q_{s t}$ for NU-125-F1 results in slightly lower uptake at

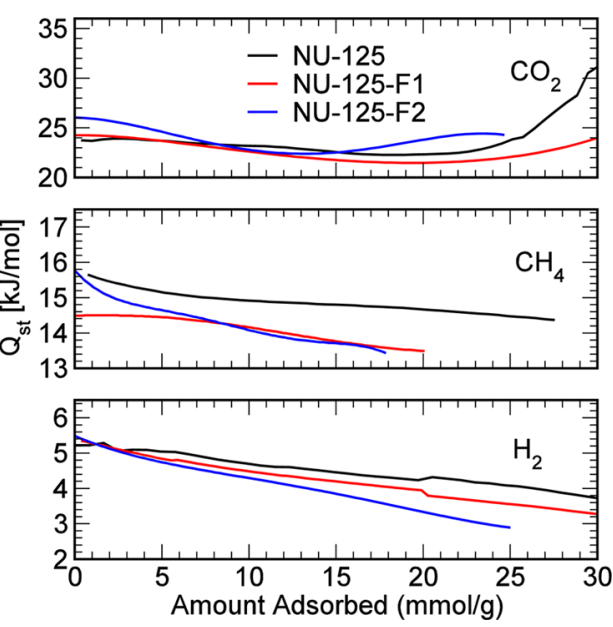

Figure 6. Comparison of isosteric heats of adsorption $\left(Q_{s t}\right)$ as a function of gas loading in $\mathrm{mmol} / \mathrm{g}$ for NU-125 (black), NU-125-F1 (red), and NU-125-F2 (blue). low pressures when compared to parent NU-125, whereas additional surface area and pore volume in NU-125-F1 increases the uptake at higher pressures, therefore resulting in a gravimetric working capacity very similar to NU-125. At high loading, NU-125 has a higher $Q_{s t}$ value than that of both NU125-F1 and NU-125-F2, which is around $13.5 \mathrm{~kJ} / \mathrm{mol}$. In the case of $\mathrm{CO}_{2}$, which has much stronger interactions than $\mathrm{H}_{2}$ and $\mathrm{CH}_{4}$, the $Q_{\text {st }}$ for NU-125-F2 is actually higher at both initial and higher loadings, suggesting that perfluorobutyl chain on the fragment $\mathbf{F} 2$ serves to increase the $\mathrm{CO}_{2}-\mathrm{MOF}$ interactions. On the other hand, for NU-125-F1, the change in $Q_{s t}$ is negligible at initial and lower loadings.

\section{CONCLUSIONS AND SUMMARY}

For two promising MOFs NU-125 and HKUST-1, based on copper paddlewheel clusters, we find that a "linker fragmentation" approach to composition modulation variation is effective for creating defects and for tuning pore volumes and surface areas. We implemented the approach in either of two ways. For the first, depending on the identity of the parent linker, incorporation of the fragment (isophthalic acid) leads to missing linkages between copper paddlewheels, or it can eliminate a copper paddlewheel cluster. Therefore, the incorporation of this fragment creates defects and increases both the surface area and pore volume. In the second case, the fragment (5-perfluorobutylisophthalic acid) carries a sterically demanding functional group. Its incorporation reduces the pore volume and surface area but provides a means for introducing new functionalities and binding sites for gas adsorption. We studied the effect of defect creation on high-pressure gas adsorption properties. In the case of HKUST-1, where both gas-copper metal and gas-framework interactions are important due to small size of cages, the net effect of defect creation is to decrease the total adsorption, even though both the surface area and pore volume are increased. There is essentially zero change, however, in the working capacity for $\mathrm{CH}_{4}$ storage. In the case of $\mathbf{N U}-\mathbf{1 2 5}$, where the cages are comparatively large, the effect of defects on the total adsorption is negligible at room temperature; the defects engender substantial increases only at lower temperatures. However, for $\mathrm{CO}_{2}$, which interacts more strongly with the MOF than does either $\mathrm{H}_{2}$ or $\mathrm{CH}_{4}$, the introduction of defect sites seems to increase the total uptake, even at room temperature. These results shed light on the nature of gas adsorption in MOFs and how it can be controlled/tuned by intentionally introducing defects. It seems reasonable to expect that defect creation by linker fragmentation will prove effective in usefully altering the sorption properties of other MOFs. Finally, we note if the parent linker is expensive and the fragment is not, then the linker fragmentation approach could potentially reduce the cost of higher pore volumes and surface areas.

\section{ASSOCIATED CONTENT}

\section{Supporting Information}

Details of linker, fragment, and MOF synthesis, various characterization measurements, and total and excess isotherms. This material is available free of charge via the Internet at http://pubs.acs.org.

\section{AUTHOR INFORMATION}

\section{Corresponding Authors}

*E-mail: j-hupp@northwestern.edu (J.T.H.).

*E-mail: o-farha@northwestern.edu (O.K.F.). 
*E-mail: taner@seas.upenn.edu (T.Y.).

\section{Author Contributions}

All authors have given approval to the final version of the manuscript.

Notes

The authors declare no competing financial interest.

\section{ACKNOWLEDGMENTS}

T.Y. acknowledges the support by the U.S. Department of Energy through Basic Energy Sciences Grant No. DE-FG0208ER46522. The Northwestern group gratefully acknowledges DOE ARPA-E and the Stanford Global Climate and Energy Project for support of work relevant to $\mathrm{CH}_{4}$ and $\mathrm{CO}_{2}$, respectively.

\section{REFERENCES}

(1) Yaghi, O. M.; O’Keeffe, M.; Ockwig, N. W.; Chae, H. K.; Eddaoudi, M.; Kim, J. Nature 2003, 423, 705-714.

(2) Férey, G. Chem. Soc. Rev. 2008, 37, 191-214.

(3) Horike, S.; Shimomura, S.; Kitagawa, S. Nat. Chem. 2009, 1, 695-704.

(4) Furukawa, H.; Ko, N.; Go, Y. B.; Aratani, N.; Choi, S. B.; Choi, E.; Yazaydin, A. O.; Snurr, R. Q.; O’Keeffe, M.; Kim, J.; Yaghi, O. M. Science 2010, 329, 424-428.

(5) Farha, O. K.; Yazaydin, A. O.; Eryazici, I.; Malliakas, C. D.; Hauser, B. G.; Kanatzidis, M. G.; Nguyen, S. T.; Snurr, R. Q.; Hupp, J. T. Nat. Chem. 2010, 2, 944-948.

(6) Farha, O. K.; Eryazici, I.; Jeong, N. C.; Hauser, B. G.; Wilmer, C. E.; Sarjeant, A. A.; Snurr, R. Q.; Nguyen, S. T.; Yazaydin, A. O.; Hupp, J. T. J. Am. Chem. Soc. 2012, 134, 15016-15021.

(7) Murray, L. J.; Dinca, M.; Long, J. R. Chem. Soc. Rev. 2009, 38, 1294-1314.

(8) Lin, X. A.; Champness, N. R.; Schröder, M. Top. Curr. Chem. 2010, 293, 35-76.

(9) Makal, T. A.; Li, J.-R.; Lu, W.; Zhou, H.-C. Chem. Soc. Rev. 2012 41, 7761-7779.

(10) Sumida, K.; Rogow, D. L.; Mason, J. A.; McDonald, T. M.; Bloch, E. D.; Herm, Z. R.; Bae, T. H.; Long, J. R. Chem. Rev. 2012, 112, 724-781.

(11) Bae, Y. S.; Lee, C. Y.; Kim, K. C.; Farha, O. K.; Nickias, P.; Hupp, J. T.; Nguyen, S. T.; Snurr, R. Q. Angew. Chem., Int. Ed. 2012, $51,1857-1860$.

(12) Bloch, E. D.; Queen, W. L.; Krishna, R.; Zadrozny, J. M.; Brown, C. M.; Long, J. R. Science 2012, 335, 1606-1610.

(13) Li, J. R.; Sculley, J.; Zhou, H.-C. Chem. Rev. 2012, 112, 869932.

(14) Sato, H.; Kosaka, W.; Matsuda, R.; Hori, A.; Hijikata, Y.; Belosludov, R. V.; Sakaki, S.; Takata, M.; Kitagawa, S. Science 2014, 343, 167-170.

(15) Lee, J.; Farha, O. K.; Roberts, J.; Scheidt, K. A.; Nguyen, S. T.; Hupp, J. T. Chem. Soc. Rev. 2009, 38, 1450-1459.

(16) Ma, L. Q.; Abney, C.; Lin, W. B. Chem. Soc. Rev. 2009, 38, $1248-1256$

(17) Wade, C. R.; Li, M. Y.; Dincă, M. Angew. Chem., Int. Ed. 2013, 52, 13377-13381.

(18) Kung, C.-W.; Wang, T. C.; Mondloch, J. E.; Fairen-Jimenez, D.; Gardner, D. M.; Bury, W.; Klingsporn, J. M.; Barnes, J. C.; Van Duyne, R.; Stoddart, J. F.; Wasielewski, M. R.; Farha, O. K.; Hupp, J. T. Chem. Mater. 2013, 25, 5012-5017.

(19) Allendorf, M. D.; Bauer, C. A.; Bhakta, R. K.; Houk, R. J. T. Chem. Soc. Rev. 2009, 38, 1330-1352.

(20) Kreno, L. E.; Leong, K.; Farha, O. K.; Allendorf, M.; Van Duyne, R. P.; Hupp, J. T. Chem. Rev. 2012, 112, 1105-1125.

(21) Lalonde, M.; Bury, W.; Karagiaridi, O.; Brown, Z.; Hupp, J. T.; Farha, O. K. J. Mater. Chem. A 2013, 1, 5453-5468.

(22) Wang, Z. Q.; Cohen, S. M. Chem. Soc. Rev. 2009, 38, 13151329.
(23) Burnett, B. J.; Barron, P. M.; Hu, C. H.; Choe, W. J. Am. Chem. Soc. 2011, 133, 9984-9987.

(24) Deria, P.; Mondloch, J. E.; Tylianakis, E.; Ghosh, P.; Bury, W.; Snurr, R. Q.; Hupp, J. T.; Farha, O. K. J. Am. Chem. Soc. 2013, 135, $16801-16804$.

(25) Karagiaridi, O.; Lalonde, M. B.; Bury, W.; Sarjeant, A. A.; Farha, O. K.; Hupp, J. T. J. Am. Chem. Soc. 2012, 134, 18790-18796.

(26) Kim, M.; Cahill, J. F.; Su, Y. X.; Prather, K. A.; Cohen, S. M. Chem. Sci. 2012, 3, 126-130.

(27) Bury, W.; Fairen-Jimenez, D.; Lalonde, M. B.; Snurr, R. Q.; Farha, O. K.; Hupp, J. T. Chem. Mater. 2013, 25, 739-744.

(28) Fei, H. H.; Cahill, J. F.; Prather, K. A.; Cohen, S. M. Inorg. Chem. 2013, 52, 4011-4016.

(29) Karagiaridi, O.; Bury, W.; Tylianakis, E.; Sarjeant, A. A.; Hupp, J. T.; Farha, O. K. Chem. Mater. 2013, 25, 3499-3503.

(30) Chen, W.; Wang, J. Y.; Chen, C.; Yue, Q.; Yuan, H. M.; Chen, J. S.; Wang, S. N. Inorg. Chem. 2003, 42, 944-946.

(31) Burrows, A. D.; Frost, C. G.; Mahon, M. F.; Richardson, C. Angew. Chem., Int. Ed. 2008, 47, 8482-8486.

(32) Burrows, A. D. CrystEngComm 2011, 13, 3623-3642.

(33) Bunck, D. N.; Dichtel, W. R. Chem.-Eur. J. 2013, 19, 818-827.

(34) Koh, K.; Wong-Foy, A. G.; Matzger, A. J. Angew. Chem., Int. Ed. 2008, 47, 677-680.

(35) Koh, K.; Wong-Foy, A. G.; Matzger, A. J. J. Am. Chem. Soc. 2009, 131, 4184-4185.

(36) Deng, H. X.; Doonan, C. J.; Furukawa, H.; Ferreira, R. B.; Towne, J.; Knobler, C. B.; Wang, B.; Yaghi, O. M. Science 2010, 327, 846-850.

(37) Park, J.; Wang, Z. Y. U.; Sun, L. B.; Chen, Y. P.; Zhou, H.-C. J. Am. Chem. Soc. 2012, 134, 20110-20116.

(38) Wu, H.; Chua, Y. S.; Krungleviciute, V.; Tyagi, M.; Chen, P.; Yildirim, T.; Zhou, W. J. Am. Chem. Soc. 2013, 135, 10525-10532.

(39) Nouar, F.; Eubank, J. F.; Bousquet, T.; Wojtas, L.; Zaworotko, M. J.; Eddaoudi, M. J. Am. Chem. Soc. 2008, 130, 1833-1835.

(40) Eubank, J. F.; Nouar, F.; Luebke, R.; Cairns, A. J.; Wojtas, L.; Alkordi, M.; Bousquet, T.; Hight, M. R.; Eckert, J.; Embs, J. P.; Georgiev, P. A.; Eddaoudi, M. Angew. Chem., Int. Ed. 2012, 51, 1009910103.

(41) Luebke, R.; Eubank, J. F.; Cairns, A. J.; Belmabkhout, Y.; Wojtas, L.; Eddaoudi, M. Chem. Commun. 2012, 48, 1455-1457.

(42) Yan, Y.; Lin, X.; Yang, S. H.; Blake, A. J.; Dailly, A.; Champness, N. R.; Hubberstey, P.; Schröder, M. Chem. Commun. 2009, 10251027.

(43) Yuan, D.; Zhao, D.; Sun, D.; Zhou, H.-C. Angew. Chem., Int. Ed. 2010, 49, 5357-5361.

(44) Farha, O. K.; Wilmer, C. E.; Eryazici, I.; Hauser, B. G.; Parilla, P. A.; O'Neill, K.; Sarjeant, A. A.; Nguyen, S. T.; Snurr, R. Q.; Hupp, J. T. J. Am. Chem. Soc. 2012, 134, 9860-9863.

(45) Peng, Y.; Srinivas, G.; Wilmer, C. E.; Eryazici, I.; Snurr, R. Q.; Hupp, J. T.; Yildirim, T.; Farha, O. K. Chem. Commun. 2013, 49, 2992-2994.

(46) Barin, G.; Krungleviciute, V.; Gomez-Gualdron, D. A.; Sarjeant, A. A.; Snurr, R. Q.; Hupp, J. T.; Yildirim, T.; Farha, O. K. Chem. Mater. 2014, 26, 1912-1917.

(47) He, Y.; Li, B.; O’Keeffe, M.; Chen, B. Chem. Soc. Rev. 2014, DOI: $10.1039 / \mathrm{C} 4 \mathrm{CS} 00041 \mathrm{~B}$.

(48) Wilmer, C. E.; Farha, O. K.; Yildirim, T.; Eryazici, I.; Krungleviciute, V.; Sarjeant, A. A.; Snurr, R. Q.; Hupp, J. T. Energy Environ. Sci. 2013, 6, 1158-1163.

(49) Chui, S. S. Y.; Lo, S. M. F.; Charmant, J. P. H.; Orpen, A. G.; Williams, I. D. Science 1999, 283, 1148-1150.

(50) Peng, Y.; Krungleviciute, V.; Eryazici, I.; Hupp, J. T.; Farha, O. K.; Yildirim, T. J. Am. Chem. Soc. 2013, 135, 11887-11894.

(51) Yan, Y.; Suyetin, M.; Bichoutskaia, E.; Blake, A. J.; Allan, D. R.; Barnett, S. A.; Schröder, M. Chem. Sci. 2013, 4, 1731-1736.

(52) Mason, J. A.; Veenstra, M.; Long, J. R. Chem. Sci. 2014, 5, 3251. 